\title{
The Design of Nozzle-Dam Work Robot in Steam Generator
}

\author{
Sang-Gug Park ${ }^{1 *}$, Young-Kyu Kwon ${ }^{2}$ and Il-Gyoum Kim ${ }^{3}$ \\ ${ }^{1 *}$ Division of Steel-IT, UIDUK University, Korea \\ ${ }^{2}$ Division of Steel-IT, UIDUK University, Korea \\ ${ }^{3}$ CHOMDAN MECHANICAL Co. LTD, Korea \\ ${ }^{1}$ skpark@uu.ac.kr, ${ }^{2} y k k w o n @ u u . a c . k r,{ }^{3}$ kimant64@naver.com
}

\begin{abstract}
In this paper, we are design an 8-axes robot arm and simulate a path to work on the mounting and dismounting of a nozzle-dam in the steam generator of a nuclear power plant. We will use 3-D modeling and structural analysis in the simulation. We will suggest location compensation algorithm for accurate positioning and collision avoidance of work robot. Also, we are design a robot control system for the servo motor drive. Through a test using the prototype robot, we will confirm that our robot will perform mounting and dismounting of nozzle-dam within the target time well.
\end{abstract}

Keywords: Nozzle-dam, steam generator, nuclear robot, nozzle-dam robot

\section{Introduction}

The nozzle-dam is a special closure that block the coolant flow from reactor at the inlet and outlet nozzles in the steam generator of a nuclear power plant [1] [4]. The Mounting and dismounting of a nozzle-dam is an essential process for inspection and maintenance in the steam generator [5] [9]. Currently, any work inside of the steam generator water chamber requires manpower, which will inevitably expose the worker to high levels of radiation during overhaul. Generally, 12 workers are assigned to a steam generator in secondary loop. Although their exposure does differ by the type of job that they have, they are supposed to be exposed to 18 36 Sievert of radiation at each unit. Therefore, multiple simulation exercises are needed for the workers. However, it is difficult to manage the required number of workers with abundant experience. Moreover, there is always a high probability of human error since very narrow space is allowed to work inside of a water chamber under the high level of radiation. To eliminate these problems, any working robots are required to replace the workers [10][11]. In this paper, we have designed an 8-axes robot arm and simulated a path to work on the mounting and dismounting of nozzle-dam in the steam generator of nuclear power plant. We will use 3-D modeling and structural analysis in the simulation. We suggest location compensation algorithm for accurate positioning and collision avoidance of work robot. Also, we have designed robot control system for servo motor drive. Through a test using the prototype robot, we have confirmed that our robot will perform mounting and dismounting of nozzle-dam within the target time well.

\section{The Environment for the Nozzle-Dam Working}

Steam generators are heat exchangers used to convert water into steam from heat produced in a nuclear reactor core. They are used in pressurized water reactors (PWR) between the primary and secondary coolant loops. Most American, Canadian, Japanese, French, and German PWR suppliers use the vertical U-tube design with inverted tubes. The vertical steam generators generally have a feed water ring supply header on the outer edge of the steam generator. Figure 1 shows

1* Corresponding author 
an overview of the vertical steam generator. The nozzle-dam is used to block the coolant flow from the reactor at the inlet and outlet nozzles in the steam generator of a nuclear power plant. Figure 2(a) shows the nozzle-dam in steam generator and figure 2(b) shows a 3-D drawing model that was cut from the bottom of the steam generator. The average weight of a nozzle-dam is about $30 \mathrm{~kg}$.

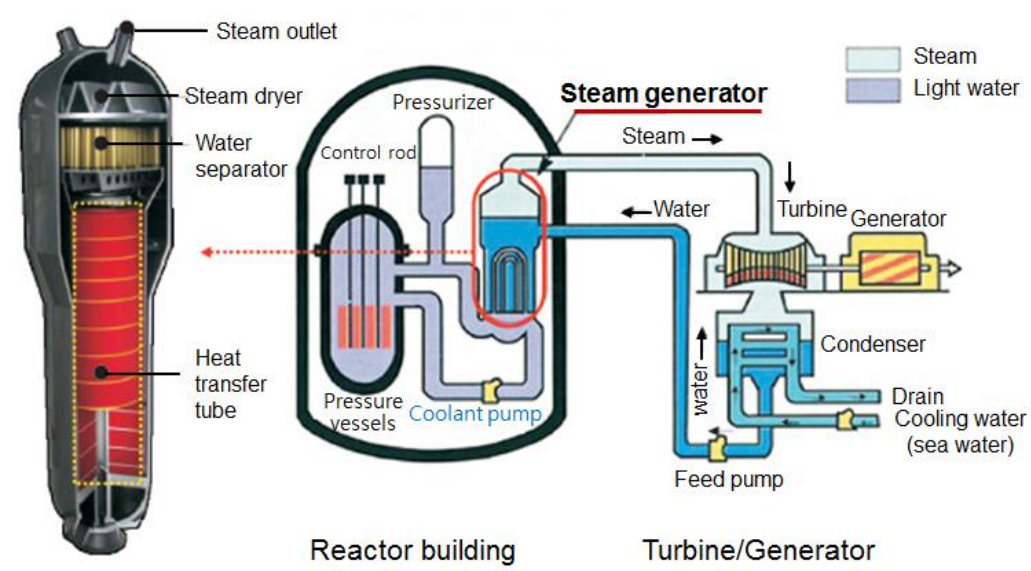

Figure 1. Overview of Steam Generator in Nuclear Power Plant System

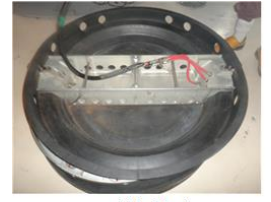

$(19.5 \mathrm{~kg})$

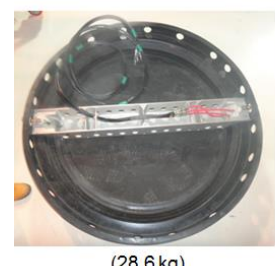

$(28.6 \mathrm{~kg})$

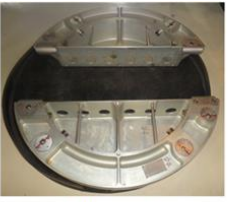

$(23 \mathrm{~kg} \times 2$ piece $)$

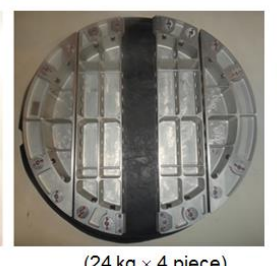

Nozzle-dam

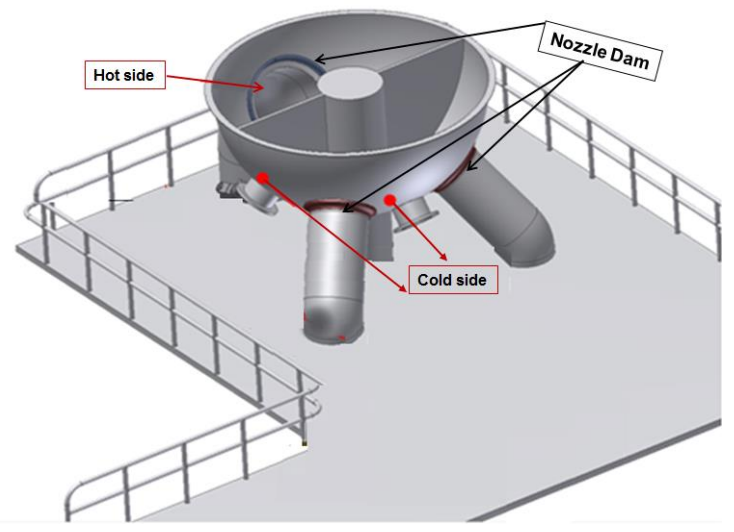

(b) 3-D drawing model

Cold side
$\left(30^{\prime \prime}, 3\right.$ piece $)$

Hot side

$(42 ", 5$ piece $)$

(a)

\section{.}


The diameter of a nozzle-dam is 30 inches on the cold side and 42 inches on the hot side. The nozzle-dam consists of 3 pieces (segments) in the cold side, and 5 pieces (segments) in the hot side.

\section{The Design of 8-axes Jointed-Arm Robot}

The robot should move to the man-way hole where workers enter and exits. The diameter of this man-way hole is about 18 inch. Therefore, the radial movement of the robot is very limited. In view of these points, we looked to the simulation work on various routes. We have designed a robot-arm with four-modules (attitude determination module, location determination module, segment module, and man-way flange mounted base operation module) for easy transport, fast assembly and simple installation. We have reduced the weight of each module to less than $30 \mathrm{~kg}$. Also, we have designed a robot as a serial-type multi-joint structure to eliminate interference. The cover and tool of a nozzledam are put over the entrance of the man-way. To calculate the dimension and joint length of the robot-arm, we have performed 2D and 3D solid works simulation.

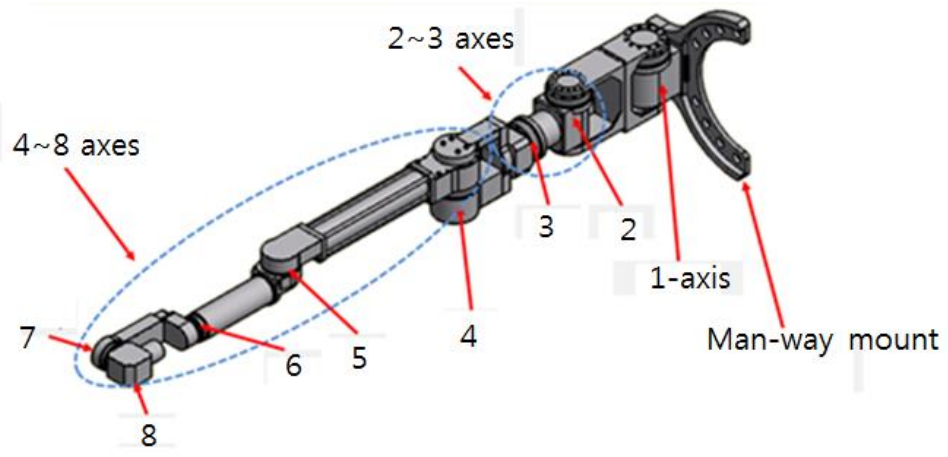

(a) 8-axes robot arm modeling

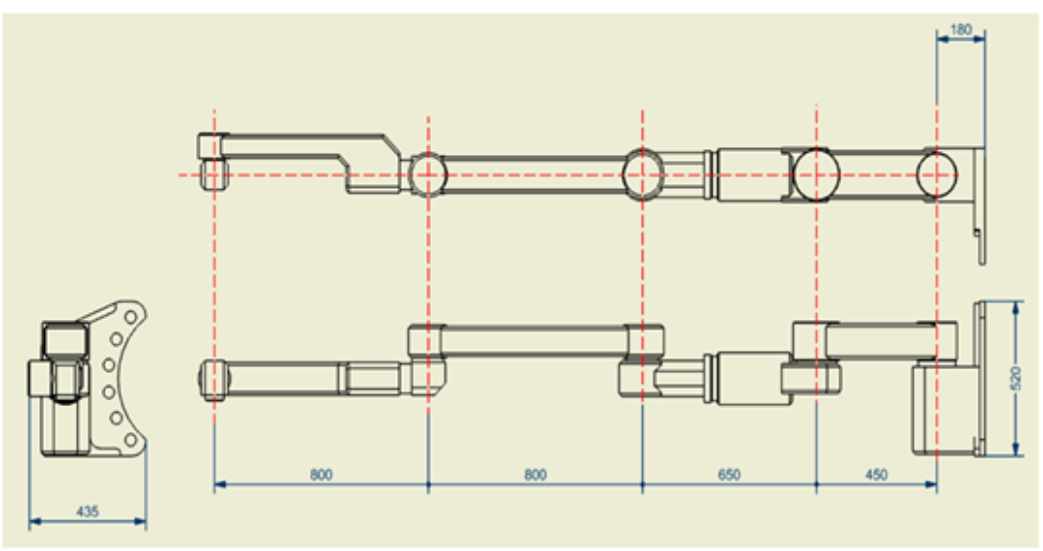

(b) Detailed design drawings

Figure 3.The Design of 8-axes Joint Arm Robot 
We have performed structural analysis about the design model of the robot-arm. In the first step, we generate mesh model (node numbers: 116,362 nodes / tetra: 67,478 elements). In the second step, we have set 3 -analysis positions (initial position, middle position, final position). In the next step, we find a minimum safety factor point and displacement size using these three positions. Through the structural analysis, we obtained maximum displacement and minimum safety values of the 3 analysis positions. The "maximum displacement/ minimum safety" values of the initial position, middle position, and final position are $2.46 \mathrm{~mm} / 10.9,4.48 \mathrm{~mm} / 6.69$, and $5.23 \mathrm{~mm} / 7.78$, respectively. From these data, we concluded our design model is safe. Figure 4 shows the results of structural analysis of the detailed design model. Figure 4(a) is the design mode of the robot-arm and figure 4(b) is its mesh model. Figure 4(c) is the result of structural analysis.

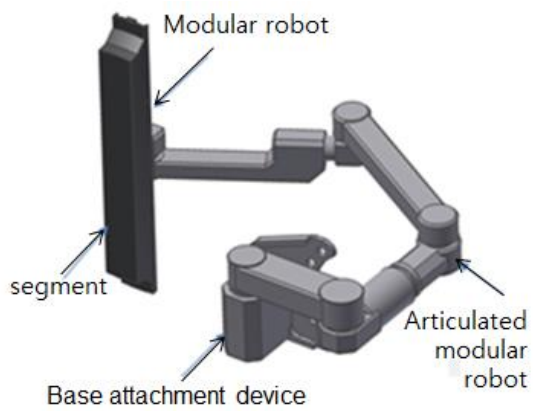

(a) Design model

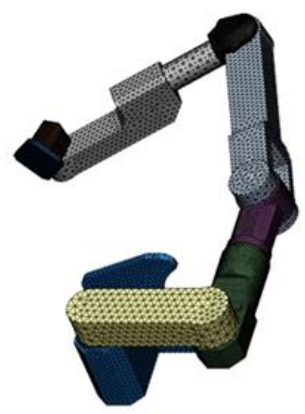

(b) Mesh model

\begin{tabular}{|c|c|c|c|}
\hline Position & $\begin{array}{l}\text { Analysis } \\
\text { shape }\end{array}$ & $\begin{array}{l}\text { Full Displacement } \\
\text { (Max.) }\end{array}$ & Safety(Min.) \\
\hline $\begin{array}{l}\text { Initial } \\
\text { Position }\end{array}$ & & & 10. \\
\hline $\begin{array}{l}\text { Middle } \\
\text { Position }\end{array}$ & & $4.48 \mathrm{~mm}$ & \\
\hline $\begin{array}{l}\text { Final } \\
\text { Position }\end{array}$ & & $23 \mathrm{~m}$ & 7.7 \\
\hline
\end{tabular}

(c) Structural analysis results

Figure 4.The Results of Structural Analysis of the Detailed Design Model 


\section{Location Compensation Algorithm}

The man-way mount of the joint-arm robot is used to the fix robot arm to the man-way pipe. The variation of mounting points leads to errors in the moving trajectory of the robot gripper. In this paper, we propose the location compensation algorithm to compensate the trajectory error of the robot arm which is associated with variation of mounting points. The laser distance measurement sensors are mounted in the segment gripper. These sensors will measure the distance between nozzle-dam mounting segment and gate circlehole which will be installed nozzle-dam. These sensors collect the following 3-points location information: upper and lower grooves information of gate circle-hole, side location information of gate circle-hole, and center and slope information of retention ring. Figure 5 shows the concept of the location compensation. In the first step, we find point A, B and C by scanning the distance measurement sensors (Scan $1 \sim$ Scan 5). Second, we produce one plane by connecting the 3-points, A, B, C and obtain the slope information. Third, we find the center point of gate circle-hole from the 3-points.

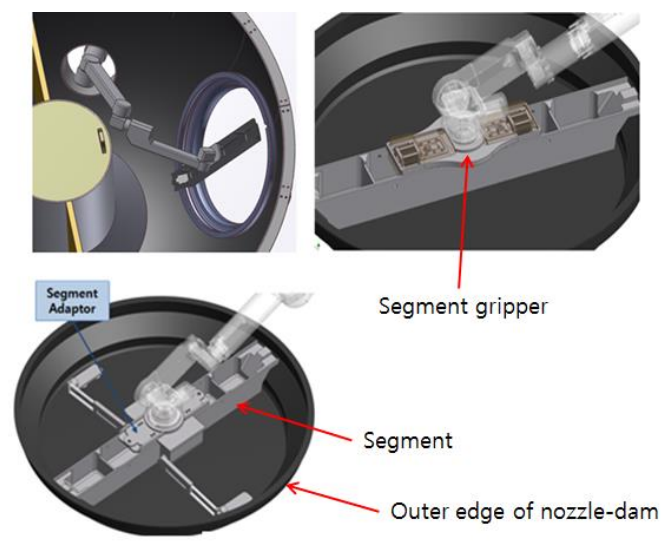

(a) Segment gripper and segment of nozzle-dam
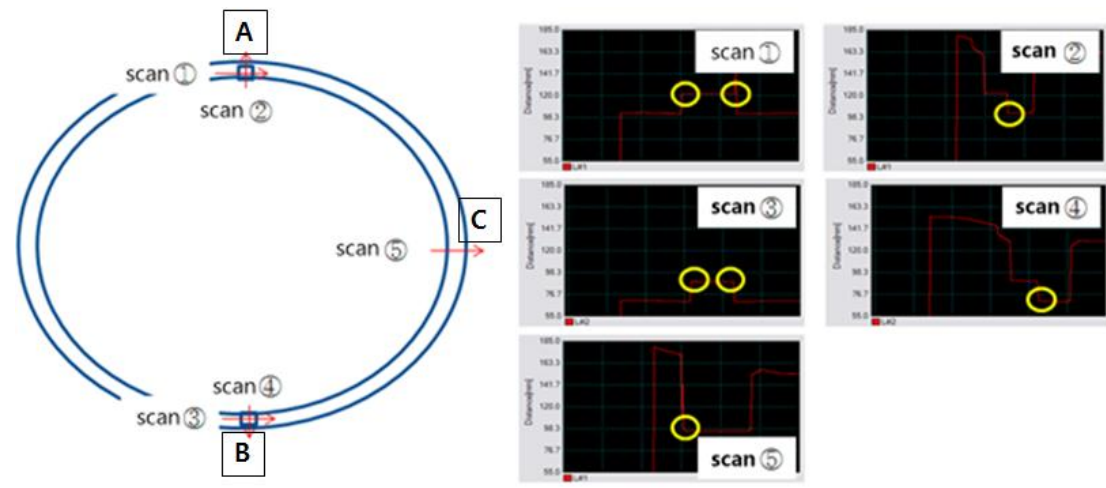

(b) Scanning point of gate circle-hole

Figure 5. The Concept to the Location Compensation 
The center point of the segment gripper is used to fix the segment gripper to the robot arm. Figure 6 shows the concept to find the center point of the segment gripper. In the first, we find the location of point P1 and P2 by the scanning the distance measurement sensor (Scan 1). In the second, we find location of point P3 by scanning sensor (Scan 2). The trajectory of "Scan 2" is perpendicular with line P1-P1 and pass by the center of line P1-P1. Point P3 is determined as a reference coordinate to fix segment gripper to the robot arm.

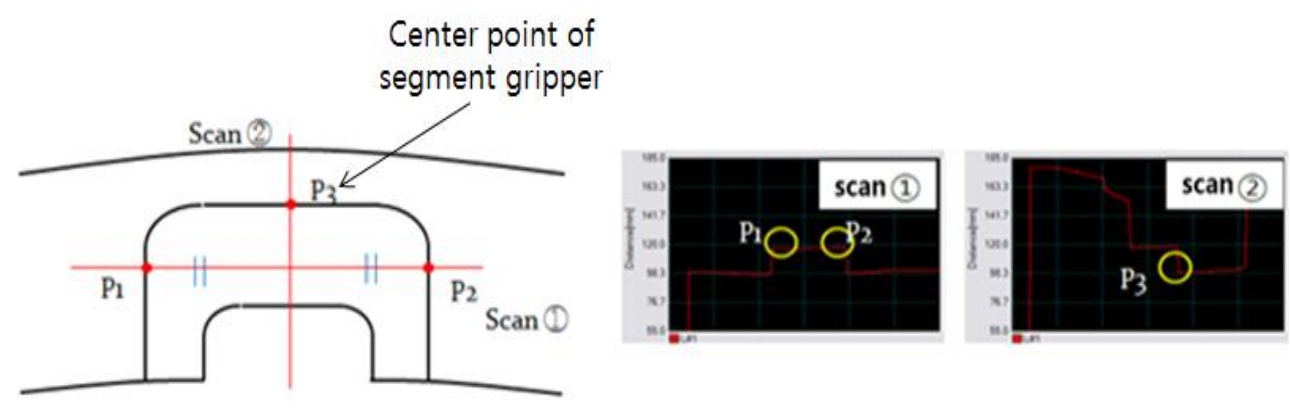

Figure 6. The Concept to Find Center Point of Segment Gripper

Figure 7 shows the concept to the find center point, $\mathrm{P}(\mathrm{x}, \mathrm{y})$ of the gate circle-hole from the 3-points, $\mathrm{A}\left(\mathrm{x}_{1}, \mathrm{y}_{1}\right), \mathrm{B}\left(\mathrm{x}_{2}, \mathrm{y}_{2}\right), \mathrm{C}\left(\mathrm{x}_{3}, \mathrm{y}_{3}\right)$. Equation (1) is an equation to obtain the perpendicular bisector of the line segment A-B. Equation (2) is an equation to obtain the perpendicular bisector of the line segment B-C. Equation (3) is a matrix representation of equation (1) and (2). From equation (3), Center coordinates $\mathrm{x}$ and y can be obtained by equation (4).

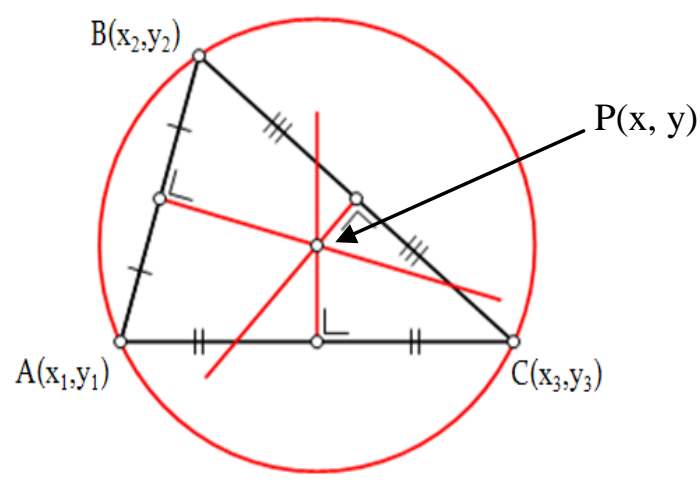

Figure 7. The Concept to Find Center Point of Gate Circle-Hole

$$
\begin{aligned}
& \left(x_{2}-x_{1}\right)\left(x-\frac{x_{1}+x_{2}}{2}\right)+\left(y_{2}-y_{1}\right)\left(y-\frac{y_{1}+y_{2}}{2}\right)=0 \\
& \left(x_{3}-x_{2}\right)\left(x-\frac{x_{2}+x_{3}}{2}\right)+\left(y_{3}-y_{2}\right)\left(y-\frac{y_{2}+y_{3}}{2}\right)=0 \\
& \left(\begin{array}{ll}
x_{2}-x_{1} & y_{2}-y_{1} \\
x_{3}-x_{2} & y_{3}-y_{2}
\end{array}\right)\left(\begin{array}{l}
x \\
y
\end{array}\right)=\frac{1}{2}\left(\begin{array}{l}
x_{2}^{2}-x_{1}^{2}+y_{2}^{2}-y_{1}^{2} \\
x_{3}^{2}-x_{2}^{2}+y_{3}^{2}-y_{2}^{2}
\end{array}\right)
\end{aligned}
$$




$$
\begin{aligned}
& \left(\begin{array}{l}
x \\
y
\end{array}\right)=\frac{1}{2}\left(\begin{array}{ll}
x_{2}-x_{1} & y_{2}-y_{1} \\
x_{3}-x_{2} & y_{3}-y_{2}
\end{array}\right)^{-1}\left(\begin{array}{l}
x_{2}^{2}-x_{1}^{2}+y_{2}^{2}-y_{1}^{2} \\
x_{3}^{2}-x_{2}^{2}+y_{3}^{2}-y_{2}^{2}
\end{array}\right) \\
& =\frac{1}{2\left[\left(x_{2}-x_{1}\right)\left(y_{\mathrm{s}}-y_{2}\right)-\left(y_{2}-y_{1}\right)\left(x_{\mathrm{s}}-x_{2}\right)\right]}\left(\begin{array}{ll}
y_{3}-y_{2} & y_{1}-y_{2} \\
x_{2}-x_{1} & x_{2}-x_{1}
\end{array}\right)\left(\begin{array}{l}
x_{2}^{2}-x_{1}^{2}+y_{2}^{2}-y_{1}^{2} \\
x_{3}^{2}-x_{2}^{2}+y_{3}^{2}-y_{2}^{2}
\end{array}\right)
\end{aligned}
$$

\section{Design of Servo Motor Driver System}

We have designed a servo motor drive interface system to control the motion of robot arm. The NI Compact RIO (cRIO-9065) is a real time processor for communication with servo-driver interface system and to the control of servo motors. The NI servo motor drive (MID-7654) can control the 8-axes of the robot arm. Also, NI Compact RIO has two Ethernet ports for the direct connection with GigE camera. Analog and digital input/output card are attached to the NI Compact RIO to measure and control analog and digital sensor devices. Figure 8 shows the NI servo-motor drive interface system for the robot-arm control. This system is the local control module of a nozzle-dam work robot. In our research, we have designed another servo drive interface system. These systems have eight servo drives connected with 8 -axes motor units.

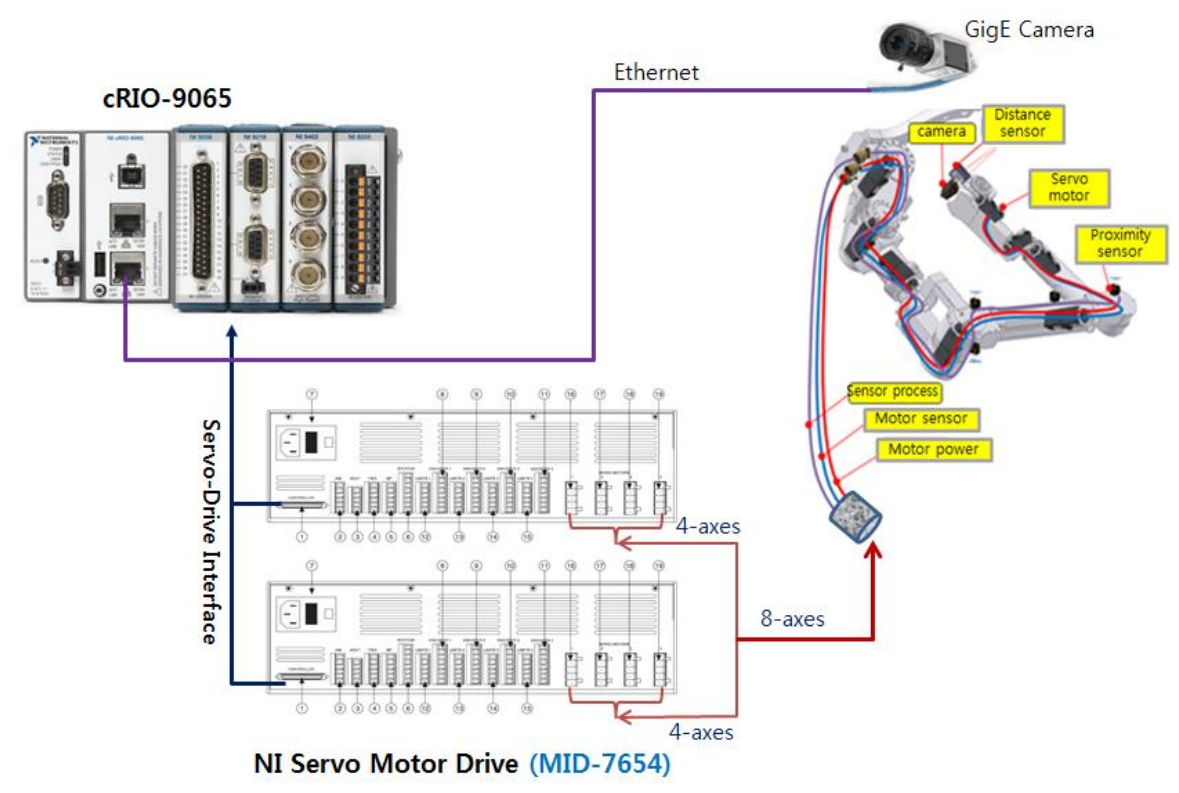

Figure 8. The Servo Motor Drive Interface System for the Robot-Arm Control

\section{Test of Nozzle-Dam Work Robot}

In this paper, we have designed an 8-axes robot arm. For accurate positioning and collision avoidance of the work robot, we have simulated via 3-D modeling. The modeling factors are nozzle-dam weight (maximum $30 \mathrm{~kg}$ per each segment) of the cold side and hot side, diameter of the cold side (30") and the hot side (42"), diameter of the man way hole (18"). For the experiment, we have developed a prototype model of nozzle-dam work robot. Figure 9(a) shows 3-D simulation model, and figure 9(b) shows a prototype model of nozzle-dam work robot. The segment of segment-gripper in figure 9(b) is a dummy segment that was made for the testing. 
The weight of the dummy segment is $30 \mathrm{~kg}$. Figure 10 shows segment test image of the nozzle-dam work robot
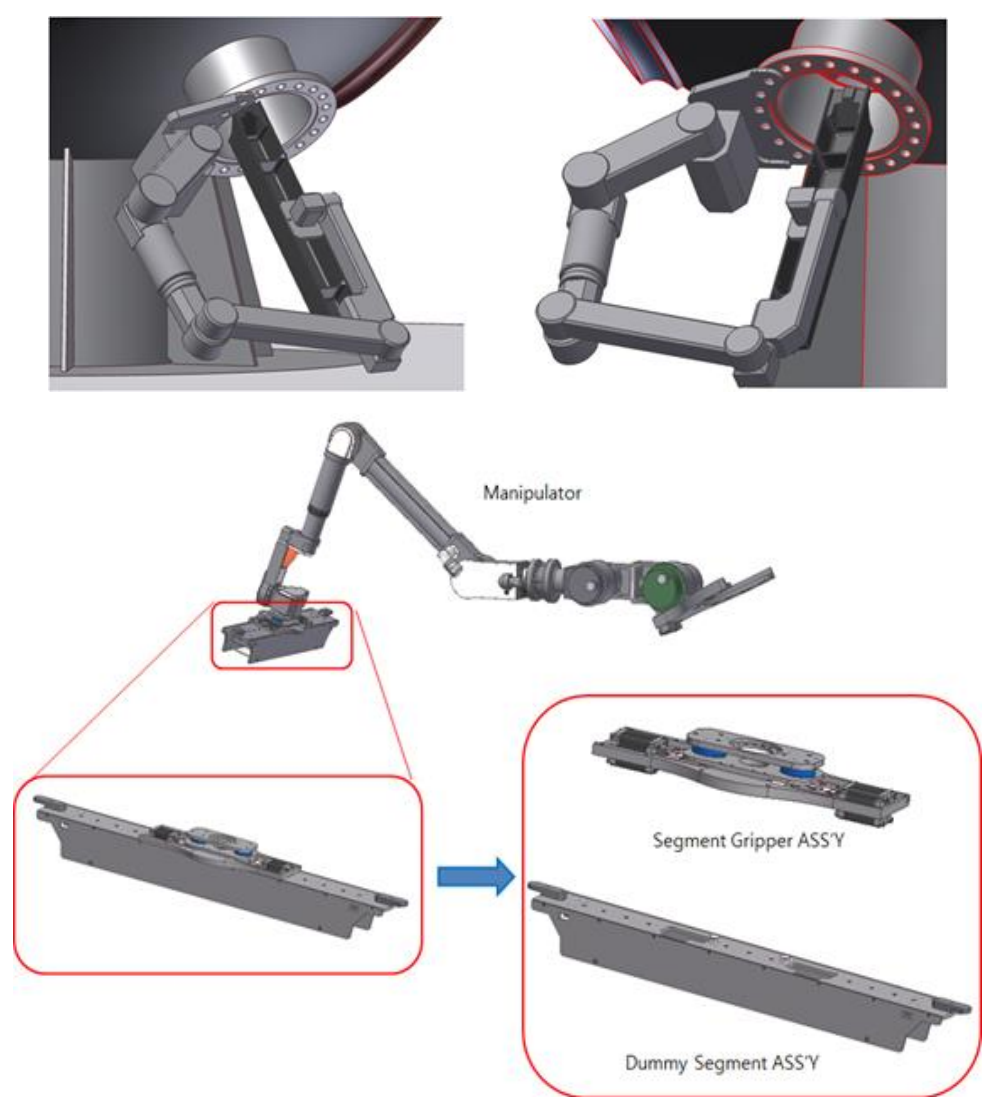

(a) 3-D simulation model

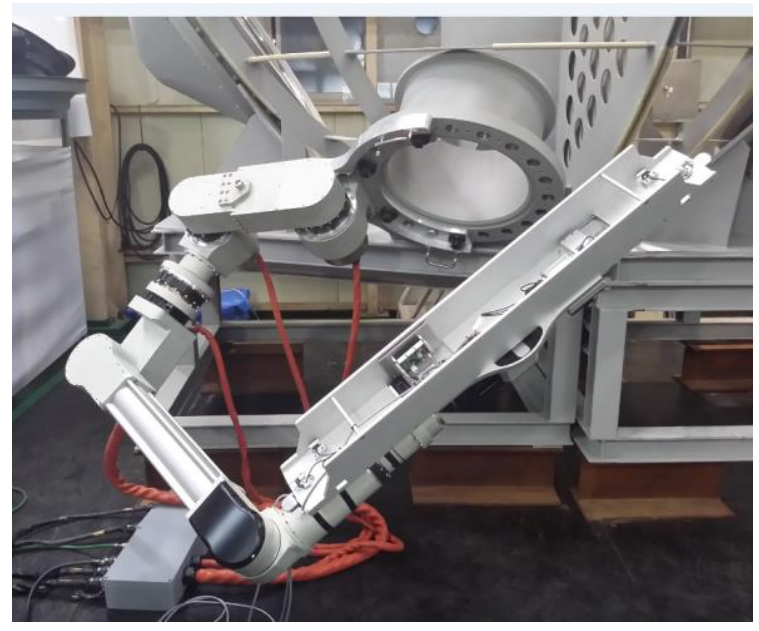

(b) Prototype model

Figure 9. Test Model of the Nozzle-Dam Work Robot 


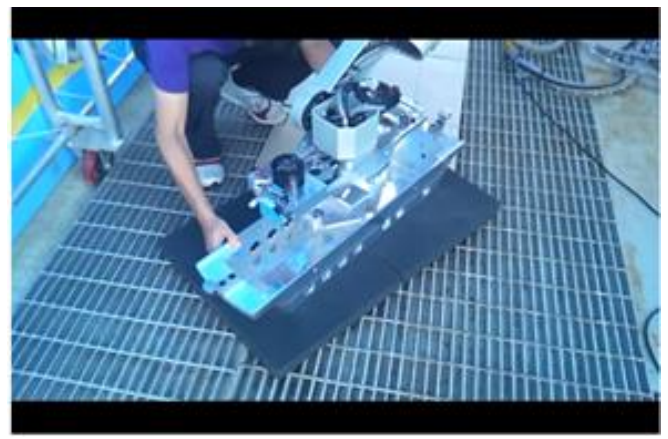

(a) Auto scanning test before install of segment
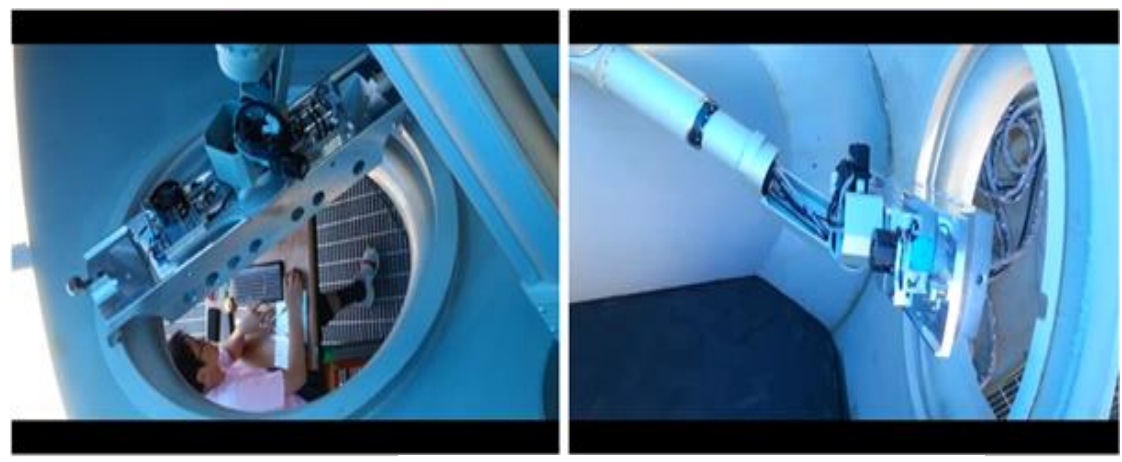

(b) Auto scanning test after install of segment
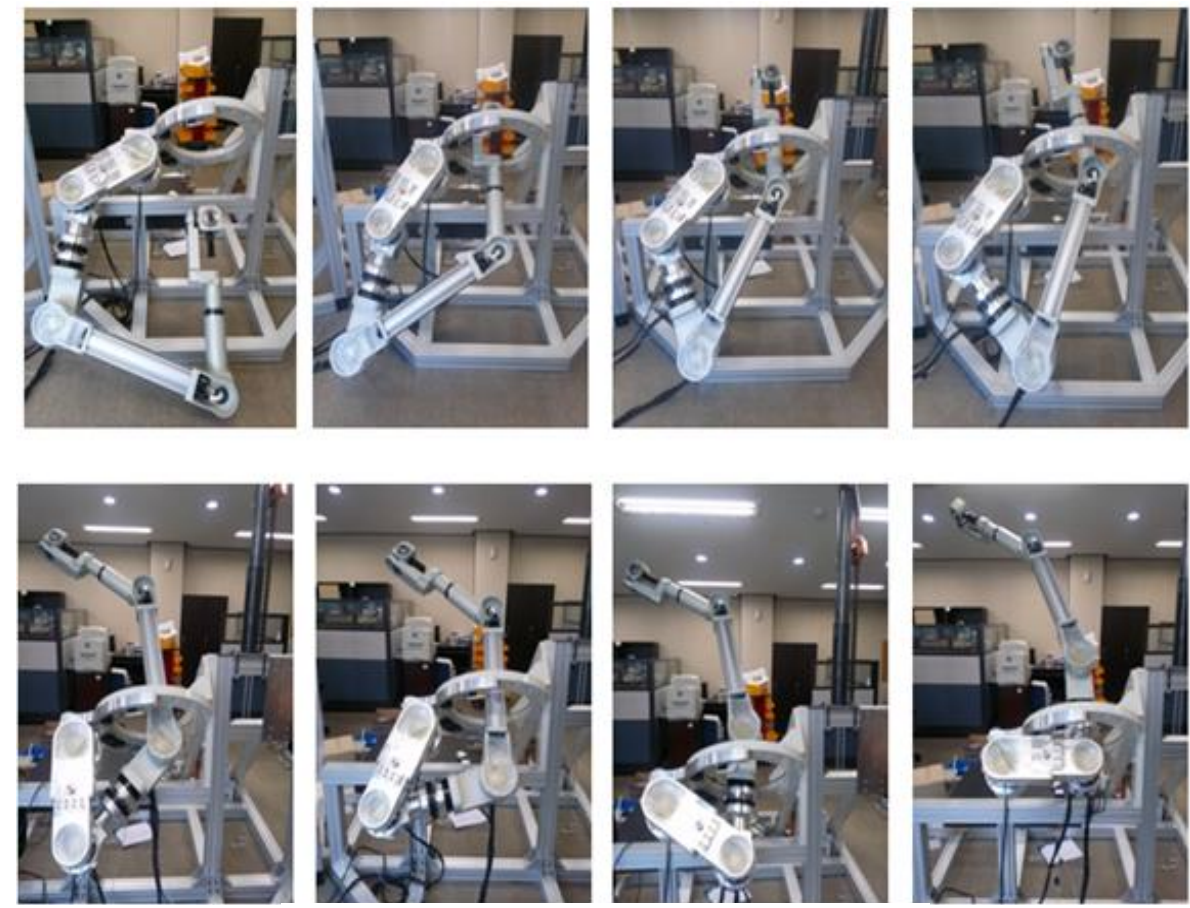

(c) Segment mounting test based on way-point

Figure 10. Segment Test of the Nozzle-Dam Work Robot 


\section{Conclusions}

In this paper, we have designed an 8-axes robot arm and simulated path to work on the mounting and dismounting of the nozzle-dam in the steam generator of a nuclear power plant. We have proposed a location compensation algorithm to compensate the trajectory error of the robot arm which is associated with a variation of mounting points. For the trajectory simulation, 3-D modeling and structural analysis were performed. We have developed a prototype model of a nozzle-dam work robot for the test. Through the test, we have confirmed that our robot perform mounting and dismounting of nozzle-dam within the target time well. In the future, we will continue the reliability test after complemented the systems.

\section{Acknowledgments}

"This research was supported by 2016 public institutions linked regional industrial development project of Ministry of Trade, Industry and Energy (No.:R0004607)"

\section{References}

[1] S. Y. Whang, C. H. Kim and S. H. Kim, "Development of Remotely Controlled Robotic System for Nozzle Dam Relating Works inside Steam Generator", '95 KACC, vol. 1, no.2, (2003), pp. 1145-1149.

[2] T. R. Kim, J. S. Park, S. H. Jung and J. H. Park, "Development of Remotely Controlled Robotic System for Nozzle Dam Relating Works inside Steam Generator", Journal of the Korean Nuclear Society, vol. 27, no.3, (1995), pp. 327-335.

[3] S. G. Park, Y.K. Kwon and I. G. Kim, "The Design of Robot-Arm for the Nozzle-dam open/close in Steam Generator", 2016 International Conference on Future Information \& Communication Engineering, Danang, Vietnam, (2016).

[4] S. G. Park, Y.K. Kwon and I. G. Kim, "The Design of Robot control system for the Nozzle-dam work in Steam Generator", 2016 International Conference on Future Information \& Communication Engineering, Danang, Vietnam, (2016).

[5] S. M. Lee, "The 3-dimensional location measurement and detection system for the mobile robot in a nuclear reactor", Doctoral thesis of Choung-nam Nation University, (2007).

[6] G. T. Park, "Study on development of tool application controller and program for multi-proposed robot in steam generator of nuclear power plant", Master's thesis of Dongmyung information University, (2004).

[7] W. H. Seo, "Design of intelligent robot system for automatic inspection and repair of steam generator of nuclear power plant", Doctoral thesis of Kyungnam University, (2001).

[8] R. Sharp and M. Decreton, "Radiation tolerance of components and materials in nuclear robot applications", Realiability engineering \& system safety, Elsevier, vol. 53, no3, (1996), pp. 291-299.

[9] L. Briones, P. Bustamante and M.A. Sema, "A Wall-climbing pneumatic robot for inspection in nuclear power plants, Elsevier, vol. 11, no. 4, (1994), pp. 287-292.

[10] S. M. Hong, D. H. Shin, J.J. Lee and B. G. Lee, "Viewing Angle-Improved 3D Integral Imaging Display with Eye Tracking Sensor", Journal of Information and Communication Convergence Engineering, vol. 12, no.2, (2014), pp. 208-214.

[11] H. J. Seo and H. W. Kim, "Study of Modular Multiplication Methods for Embedded Processors", Journal of Information and Communication Convergence Engineering, vol. 12, no.3, (2014), pp. 145153. 


\section{Authors}

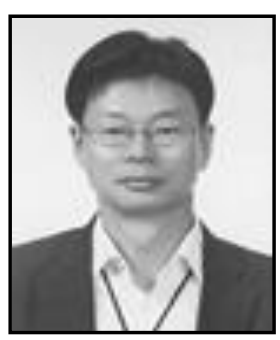

Sang-Gug Park,

- 1996 2000 Kyungpook National University, Korea (Ph.D)

- 1989 1993: Samsung Electronics Co. LTD

- 1994 2001: RIST

- 2001 2014: Dep. of Computer Engineering, Uiduk University

- 2015 Now: Div. of Steel-IT Engineering, Uiduk University

- Research area: DSP, Robot vision

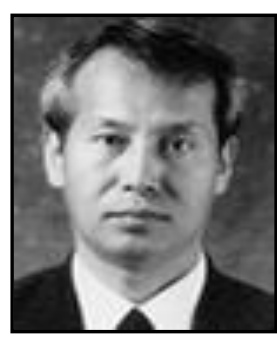

Young-Kyu Kwon,

- Keio University, Japan (Ph. D)

- 1989 1996: RIST

- 1997 2014: Dep. of Electronics Engineering, Uiduk University

- 2015 Now: Div. of Steel-IT Engineering, Uiduk University

- Research area: VLSI process, Photo Electronics

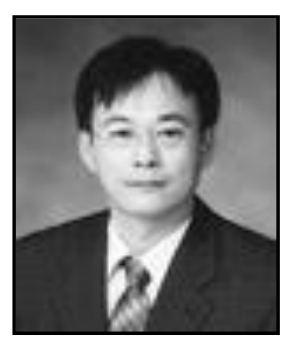

Il-Gyoum Kim,

-2000:Dep. of Mechanical Engineering, Inha University, Korea(Ph. D)

- 2004 2010: Kang-Nam Filter Co. LTD

- 2012 Now: CHOMDAN Mechanical Co. LTD

- Research area: Robot system, Industrial machine equipment 
International Journal of Control and Automation

Vol. 10, No. 1 (2017) 